\title{
Achalasia: What is the Best Treatment?
}

\author{
Adamu Ahmed
}

Division of General Surgery, Department of Surgery, Ahmadu Bello University Teaching Hospital, Zaria, Nigeria Reprint requests to: Dr. Adamu Ahmed, Department of Surgery, Ahmadu Bello University Teaching Hospital, Zaria, Nigeria. E-mail: mrahmed1010@yahoo.com, Tel.:+234-803-7200894

\begin{abstract}
Background: Achalasia is an infrequent primary motility disorder of the esophagus. Because of uncertain etiology, treatment is only palliative and is directed at decreasing lower esophageal sphincter pressure, improving esophageal emptying and relieving the symptoms of achalasia. Current treatment options include pharmacological, endoscopic and surgical. We undertook a systematic literature review of the management strategies currently available for achalasia.

Method: A Medline, PubMed and Cochrane database search was conducted using reference manager 11. Original articles and reviews published in the English literature on the management of achalasia were reviewed. Emphasis was placed on articles published in the last ten years on randomized controlled trials comparing the various forms of treatment.

Results: Esophageal manometry is the standard diagnostic evaluation for achalasia. Accurate diagnosis can also be made based on clinical findings and barium esophagogram. Medical treatment with nitrates or calcium channel blockers has variable results in alleviating the symptoms of achalasia but long-term results are disappointing because of tolerance and side effects. Intrasphincteric injection of botulinum toxin, pneumatic dilatation and surgical myotomy are variably effective at controlling the symptoms of achalasia but each modality has specific strength and weaknesses which make their choice suitable in a particular group of patients. While pneumatic dilatation is superior to botulinum toxin injection surgical myotomy provides the best long-term control of symptoms in patients with achalasia.

Conclusion: Laparoscopic myotomy should be the initial treatment for most patients with achalasia. Pneumatic dilatation is the most cost-effective alternative but its long-term efficacy is less than that of surgical myotomy. Endoscopic botulinum toxin injection can be considered when other forms of treatment are contraindicated.
\end{abstract}

Key words: Achalasia, Heller's esophagomyotomy, pneumatic dilatation

\footnotetext{
Résumé

Contexte: L'achalasie est une rare anomalie motrice de l'œsophage. En raison de son étiologie incertaine, le traitement est seulement palliatif et vise la réduire la pression sphinctérienne du bas œsophage, l'amélioration de la vidange et le soulagement des symptômes de l'achalasie. Les options thérapeutiques courantes font appel aux moyens pharmacologiques, endoscopiques et chirurgicaux. Nous avons effectué une revue systématique de la littérature relative aux stratégies thérapeutiques actuellement disponibles pour l'achalasie.

Méthode: Une recherche sur Medline, Pubmed et Cochrane a été faite a l'aide du logiciel Reference Manager 11. Les articles originaux et les rapports portant sur la prise en charge de l'achalasie et publiés en anglaise ont été passés en revue. L'accent a été mis sur les articles publiés au cours des dix dernières années et sur les essais contrôlés comparant les diverses formes de traitement.

Résultats: La manométrie œsophagienne est la méthode de diagnostic standard pour l'achalasie. Le diagnostic peut être affiné sur la base des données cliniques et du transit œsophagien. Le traitement médical avec les nitrates ou les inhibiteurs des canaux calciques donnent des résultats variables sur l'amélioration des symptômes de l'achalasie, mais les résultats à long terme sont décevants en raison
} 
de la tolérance et des effets secondaires. L'injection intra sphinctérienne de toxine botulique, la dilatation pneumatique et la myotomie chirurgicale ont une efficacité variable sur le contrôle des symptômes d'achalasie. Chaque méthode a ses avantages et ses inconvénients ce qui rend leur choix adapté pour un groupe donné de patients. Alors que la dilatation pneumatique est meilleure que l'injection de toxine botulique, la myotomie chirurgicale donne le meilleur contrôle des symptômes chez les patients ayant une achalasie.

Conclusion: La myotomie laparoscopique devrait être le traitement initial pour la plupart des patients ayant une achalasie. La dilatation pneumatique est la moins onéreuse des alternatives mais son efficacité a long terme est moindre que celle de la myotomie chirurgicale. L'injection endoscopique de toxine botulique peut être envisagée lorsque les autres formes de traitement sont contre indiquées.

Mots clés: Achalasie, esophagomyotomie de Heller, dilatation pneumatique

\section{Introduction}

The original description of achalasia was first made in 1674 by Sir Thomas Willis when he used whalebone to dilate the esophagus of a patient who was unable to swallow because of failure of the lower esophageal sphincter to relax. ${ }^{1}$ Achalasia is a benign idiopathic disorder caused by progressive neuronal degeneration of the myenteric plexus of Auerbach. ${ }^{2,3}$ It is the commonest primary esophageal motility disorder. The pathophysiology of the process represents a selective loss of inhibitory nerves that result in unopposed stimulation of the smooth muscle fibers of the LES. The etiology of primary achalasia remains controversial. Histological examination of the esophagus in achalasia suggests that the reduction in intramural ganglion cells may be a secondary change probably due to inflammation triggered by autoimmune mechanism or a chronic degenerative process of the central or peripheral part of the vagus nerve. ${ }^{4}$ The primary lesion could also be a severe myopathy of the smooth muscle cells. ${ }^{4,5}$ Familial occurrence and association with class II HLA antigens also suggest genetic predisposition. ${ }^{6,7}$

A secondary form of achalasia is Chagas disease, an infectious disease cause by the parasite Trypanasoma Cruzi. It seen mainly in Central and South America where an estimated 11 million people are infected. ${ }^{8}$ In developed countries the incidence of achalasia is 1 in 100000 individuals. ${ }^{9}$ In sub-Saharan Africa, 3 to 4 patients are seen per year. ${ }^{10-12}$ Among other esophageal diseases, achalasia is observed in $3.1 \%$ - $20 \%$ of cases and is second to gastrooesophageal reflux (GER) as the commonest functional esophageal disorder requiring surgical therapy. ${ }^{13,14}$

In developing countries the peak incidence is in the third decade, a decade lower than in developed countries. $^{10,13}$ Typically, patients present with longstanding progressive dysphagia for both liquid and solid. Regurgitation of undigested food is common and may result in aspiration and recurrent respiratory tract infection. Retrosternal pain is a prominent feature and may result from GER. ${ }^{15}$ More commonly it results from food stagnation and bacterial growth in the distal esophagus or fermentation of retained food. ${ }^{15,16}$ Weight loss is seen in $68 \%$ of patients and may be severe. ${ }^{17}$ In developed countries manometric diagnosis is obtained before therapeutic intervention. ${ }^{18}$

The most important finding is aperistalsis of the body of the esophagus in the distal smooth muscle segment of the esophagus. ${ }^{14,19}$ Other manometric findings that are characteristic but not necessary for the diagnosis of achalasia are failure or incomplete relaxation of the LES with swallowing, sustained hypertension of the LES and elevated intra esophageal body pressure compared to pressure within the stomach. ${ }^{14,18,19}$ Barium swallow is an important diagnostic tool in patients with symptoms suggestive of achalasia. Fluoroscopy reveals repetitive non-peristaltic contractions of the esophagus. $^{14,19}$ As the disease progress there is continuous dilatation of the esophagus until it become tortuous or even sigmoid in appearance (Figure 1). Twenty-four hour $\mathrm{pH}$ monitoring is also routinely used. ${ }^{20}$ Oesophageal manometry, barium swallow and $\mathrm{pH}$ - metry are also used for objective evaluation of outcome of treatment. Other diagnostic evaluations include esophagogastroduodenoscopy, trans-abdominal and high frequency intraluminal esophageal ultrasonography. ${ }^{20,21}$ Chest x-ray may show mediastinal widening, presence of air-fluid level in the mid-esophagus, absence of gastric air bubble and abnormal pulmonary markings due to chronic aspiration (Figure 2). In our setting as in others with limited facilities, diagnosis of achalasia is made to a high degree of accuracy given the symptom complex of long-standing dysphagia, regurgitation and weight loss with barium swallow showing delayed emptying, dilatation of esophageal body and the classic bird beak deformity of the distal esophagus. ${ }^{10-12}$

\section{Modalities of Treatment}

Since the early treatment of achalasia in the 17th century, surgeons have made a significant advancement in the treatment of this disease and the resultant outcomes have improved. Because the 
etiology of achalasia is not known therapy is directed at relieving dysphagia and preventing stasis related complications by reducing the outflow resistance caused by the dysfunctional LES so that force of gravity would be enough to transport food into the stomach. Medical treatment, botulinum toxin (BTox) injection, pneumatic dilatation (PD) and surgical myotomy are the modalities currently available to achieve this goal.

Figure 1. Sigmoid shape esophagus in endstage achalasia

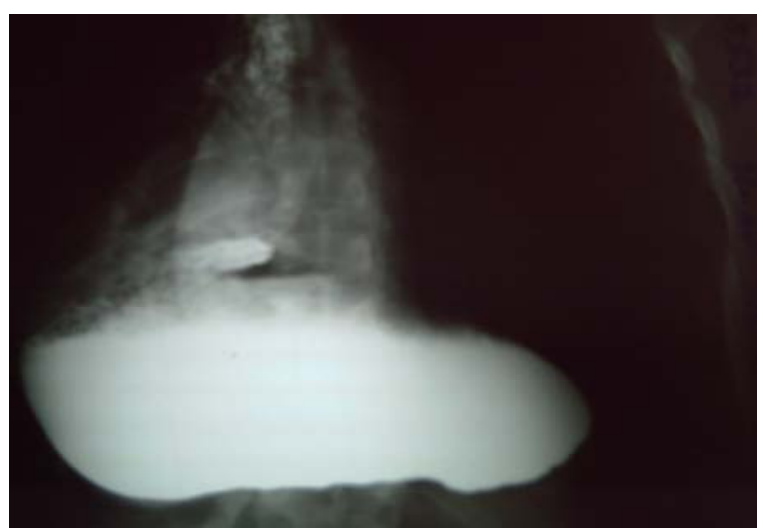

Figure 2. Chest x-ray of a patient with achalasia

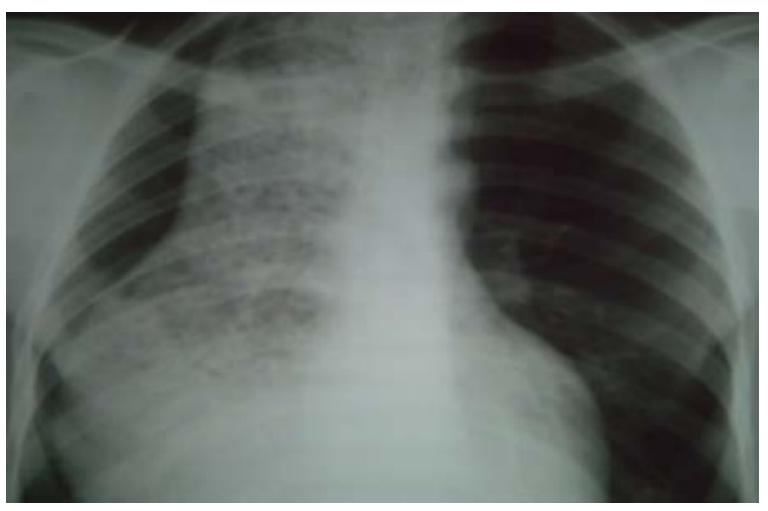

\section{Medical treatment}

Calcium channel blockers and nitrates are the drugs commonly used to treat achalasia. ${ }^{22-24}$ Calcium channel blockers inhibit cellular calcium uptake and as calcium is necessary for contraction, relaxation occurs. Nifedipine given at a dose of $20 \mathrm{mg}$ reduces the LES pressure by 30 to $40 \%{ }^{24,25}$ Nitric oxide is the measure neurotransmitter release from the myentric neurons that induces swallow and esophageal distension induced LES relaxation. ${ }^{22}$ Nitrate acts by compensating for the decrease in the inhibitory neurotransmitter. ${ }^{22}$ Both nifedipine and isosorbide dinitrate are given sublingually 30 to 60 minutes before meals. These drugs have variable results in alleviating the symptoms of achalasia with initial improvement rate of 50 to $90 \%{ }^{26}$ However, long term use of these drugs is associated with tolerance which severely decreases their effects over time. ${ }^{25}$ Nifedipine has induced long term remission and even normalization of physiology in a few patients. ${ }^{26}$ Unfortunately the common side effects of hypotension, headache and peripheral edema occur in about $30 \%$ of patients taking calcium channel blockers or nitrates and this limits their clinical use. $^{14,22}$ Sildenafil has been considered for the treatment of achalasia but because of significant side effects its clinical use has been abandoned. ${ }^{27}$ It inhibits phosephodiasterase type 5 , which prevent the destruction of nitric oxide-stimulated cyclic guanisine monophosphate. ${ }^{22,27}$ This action leads to decrease in the resting LES pressure in patients with achalasia but to a lesser extent than nifedipine. ${ }^{14}$

Medical treatment has limited efficacy in patients with achalasia. It is recommended only to patients as a bridge to more definitive treatment or to those in whom other treatments are contraindicated. ${ }^{14,22}$

\section{Endoscopic botulinum toxin injection}

Botulinum toxin is a neuro toxin that causes sustained inhibition of neurotransmitter release at cholinergic terminals. The toxins specifically bind the presynaptic membrane and enter the cystol of the nerve terminal where they cleave different proteins involved in neuroexocytosis. ${ }^{28,29}$ Botulinum toxin- A which is used for the treatment of achalasia cleaves the SNAP-25 molecule of the presynaptic membrane, thus blocking acetylcholine $(\mathrm{ACH})$ release. ${ }^{29,30}$

In the early nineties, Pasrich and colleagues evaluated the usefulness of intrasphincteric injection of BTox in achalasia patients. ${ }^{31,32}$ The rationale was that the selective loss of inhibitory nerves in achalasia upset the excitatory cholinergic influences on the LES. ${ }^{29}$ Thus by blocking the release of $\mathrm{ACH}$, locally injected BTox might reduce the LES pressure and improve passive esophageal emptying. ${ }^{29,33}$ The toxin is injected through a standard schelerotherapy needle during an upper endoscopy performed under conscious sedation. ${ }^{34}$ Usually, 80 to 100 units of BTox- A are injected in each quadrant of the LES in 0.5 to $1 \mathrm{ml}$ aliquots. ${ }^{28}$ This improves the symptoms of achalasia, decrease LES pressure, increase lower esophageal aperture and improve esophageal emptying. ${ }^{31}$ The clinical effects of a single injection are short lived with relapse in more than $50 \%$ within 6 months. ${ }^{28}$ However, repeated injections may confer clinical benefit in $70 \%$ to $90 \%$. $^{32}$ In one report, $21 \%$ of newly diagnosed achalasia patients were treated with BTox as the initial modality of treatment with an average duration of effect of 6 months. ${ }^{33}$ This waning of efficacy over time is may be related to development of autoimmune response with production of antibodies against BTox. ${ }^{31}$ Predictors of good response to BTox injection are age less than 50 years, vigorous achalasia, an initial clinical response to BTox injection and decrease in LES pressure in response to BTox injection. ${ }^{22,35}$ 
Endoscopic injection of BTox is remarkably safe. About $10 \%$ of patients develop chest or epigastric pain shortly after injection but usually does not require specific treatment. ${ }^{14,28}$ Treatment with BTox confers beneficial effects on subsequent pneumatic dilatation which is actually enhanced. ${ }^{22,31}$ However, repeated injection of the toxin makes subsequent surgical myotomy more difficult due to adhesions of the muscular layers to mucosal plane with an increased danger of mucosal perforation. ${ }^{14,33}$ Given its safety profile, BTox injection may be given to patients who are not candidates for PD or surgery and those whose life expectancy does not exceed 2 years. $^{30,35}$

\section{Pneumatic dilatation}

Historically, dilatation was the first attempt at treatment of achalasia.1 The principle is to weaken the LES by tearing its muscle fibers by generating radial force from within the esophagus. In the past, a variety of mercury filled buggies, hydrostatic dilators and metallic devices were used with varying degree of success. Modern dilators consist of expanding balloons that forcefully dilate the LES. Pneumatic dilatation is currently the most effective non- surgical treatment of achalasia. ${ }^{14,17}$ However variations exit as to the type of dilators, fluoroscopic or endoscopic positioning of the balloon and the degree and duration of dilatation. ${ }^{34,36,37}$ Pneumatic dilatation is performed in the endoscopy suite under conscious sedation. Single dilatation with Rigiflex dilator resulted in $60 \%$ reduction in LES pressure and resolution of symptoms in $70 \%$ of patients. ${ }^{34}$ However, graduated dilatation results in a higher and more durable clinical response. ${ }^{37,38}$ A report from Cleveland clinic showed that $41 \%$ of newly diagnosed achalasia patients were initially treated with PD. ${ }^{33}$ The clinical response was $86 \%$ in these patients with improved esophageal emptying of $54 \%{ }^{33}$

Pneumatic dilatation has the advantage of achieving symptom relief while avoiding the risk associated with invasive surgery. In addition, it can be safely used when BTox injection or surgery have failed. ${ }^{22}$ The major problem of PD is the relatively high mortality rate of 1 to $2 \% .{ }^{14,34}$ Gastrooesophageal reflux is seen in $4 \%$ to $16 \%$ of patients. 34 Perforation occurs in $1 \%$ to $3 \%$ of patients many of who would require emergency surgery. ${ }^{38}$ The risk of perforation is highest during the initial dilatation as oppose to subsequent dilatation especially in patients with vigorous achalasia.38 Predictors of good outcome of PD include age above 50 years and more than $50 \%$ reduction in LES pressure. ${ }^{22,38}$ Overall, PD provides a safe and effective way of achieving long-term control of symptoms in patients with achalasia.

\section{Surgical treatment}

Historically, the treatment of achalasia by cardiomyotomy was first designed by Gottstein in
1901. ${ }^{39}$ However, in 1913 Heller acclaimed the procedure by performing it abdominally on the anterior and posterior esophageal walls. ${ }^{40}$ Currently, the universally accepted surgical treatment of achalasia is the Heller myotomy, as modified by Zaaijer. ${ }^{41}$ Myotomy became the surgery of choice to treat achalasia because of it simple technique on the anterior wall of the esophagus accessed either by the abdominal or thoracic root, by open or minimally invasive surgery. In either case, the abdominal root is preferred because the surgical set-up is easier and anesthesia is simpler because single lung ventilation is not required. ${ }^{10}$ Postoperative management of the patients is easier and they leave the hospital earlier. The abdominal approach also provides opportunity to diagnose and treat associated intra abdominal diseases. $^{42-44}$ Laparoscopic esophagomyotomy was first described in $1991 .^{45}$ This procedure is associated with significant decrease in dysphagia and low complications rate. It provides symptoms relief in about $90 \%$ of patients with more than $80 \%$ remaining dysphagia free at 5 years. ${ }^{18,46}$ However, the high cost of this approach, access to reference centers, the need of surgical skills that are not readily available and surgeon learning curve are still an issue. Recently, computer enhanced robotic telesurgery provides further improvement over laparoscopic Heller myotomy. ${ }^{47}$

Open esophagomyotomy is associated with relapse rate of less than $10 \%$ at 9 years and is currently the modality with which other forms of treatment are compared. ${ }^{44}$ In developing countries where facilities for laparoscopic approach are not readily available Heller myotomy performed by laparotomy represent a reliable and effective surgical treatment for achalasia, with good to excellent palliation of dysphagia in more than $80 \%$ of patients. ${ }^{11,12}$ The methods of assessing completeness of division of the LES fibers during myotomy are intra operative endoscopy and manometry. ${ }^{14,48}$ Endoscopic view allows precise identification of the squamocolumnar junction and guides the proximal and distal extent of the myotomy and also detects perforations that can be repaired immediately. ${ }^{14}$ Manometry on the other hand gives a more functional assessment of the myotomy and can be use to locate areas of residual high pressure zone. ${ }^{48}$

The role of antireflux procedure following esophagomyotomy remains controversial. Opponents of antireflux procedure argue that a good postoperative LES pressure with low incidence of reflux symptoms can be achieved without fundoplication by avoiding excessive posterior dissection and limiting the myotomy to 0.5 to $1 \mathrm{~cm}$ onto the stomach. ${ }^{10,49} \mathrm{~A}$ recent meta-analysis on 21 studies involving 601 patients concluded that the rates of GER was not statistically different in patients who had myotomy with partial fundoplication compared to those without fundoplication. ${ }^{50}$ 
Lopushinsky and Urbarch also did not find any difference in the pattern of antireflux medication use between patients who had antireflux procedure as part of a surgical myotomy and those who did not. ${ }^{38}$ Therefore, while Heller myotomy and fundoplication may be safe the need for the antireflux procedure is unknown. It is generally accepted that a complete $360^{\circ}$ wrap Nissen fundoplication should be avoided because it creates a high pressure zone in the distal esophagus which negates the intent of the operation. $^{50}$

The commonest antireflux procedure added to Heller myotomy is the Dor anterior $180^{\circ}$ fundoplication. ${ }^{14,46,51}$ This is associated with low rate of GER as determined by 24-hour pH monitoring.46 Suturing the gastric wall to the edges of the myotomy according to the Dor technique also maintains the edges of the myotomy open, thus preventing the consequences of scar tissue repair and covers any undetected perforation of the esophageal mucosa thus preventing any significant postoperative morbidity. ${ }^{14,51}$ Many surgeons consider the Dor technique an inadequate procedure and instead use a posterior $270^{\circ}$ Toupet fundoplication. ${ }^{19,22}$ This provides excellent relief of dysphagia with low rate of postoperative reflux. ${ }^{19}$

\section{Choice of Treatment}

In deciding to treat a patient with BTox injection, PD or surgical myotomy, there are a number of considerations including the risk of the procedure, its relative effectiveness in treating the symptoms of achalasia and the risk of treatment consequences such as GER. Several randomized trials have compared these 3 accepted modalities of treatment and clarified the best treatment for achalasia. They all concur that a myotomy or PD are superior to BTox injection. ${ }^{2,28,33,52,53}$ These studies have shown that BTox and PD are equally effective in the short-term but long-term relief of symptoms requires repeated injection of BTox. ${ }^{52,53}$ Comparison of surgical myotomy and BTox injection also revealed that the probability of being symptom-free at two years was $87.5 \%$ after surgery and $34 \%$ after BTox.33 Surgical myotomy has better long-term control of symptoms and fewer complications when compared to PD. A recent population based study reported that both Heller myotomy and PD provided good relief of symptom. $^{38}$ However, the cumulative risk of subsequent intervention for achalasia at 10 years was $63.5 \%$ for patients initially treated with PD compared to $37.5 \%$ for patients initially treated with surgical myotomy. ${ }^{38}$ Although many studies indicate that surgical myotomy is superior to PD in providing long term relief of symptoms, a few physicians still favor PD because of the relatively higher risk associated with open surgical myotomy. ${ }^{33,38,44}$ However, surgical myotomy has regained primacy because of the immense success of laparoscopic Heller myotomy which is associated with low morbidity, shorter hospital stay, faster convalescence and less postoperative pain. ${ }^{52}$ When cost analyses were performed, PD was found to be the most costeffective treatment in otherwise healthy populations. ${ }^{54}$ In patients with other co-morbidities that decrease the life expectancy to less than 2 years, BTox is more cost-effective. ${ }^{22,54}$ Although surgery is the most effective treatment for achalasia it is the most costly over the initial period of treatment. ${ }^{33,54}$

Dysphagia following cardiomyotomy can be either persistent or recurrent. Following incomplete myotomy or the addition of a tight fundoplication, dysphagia remains practically unaltered soon after operation or there may be only minor improvement. $^{55,56}$ Dense adhesions and fibrotic healing at the site of myotomy are the causes of relapse of dysphagia in the relatively late postoperative period. ${ }^{56}$ Persistent or recurrent dysphagia can be treated by endoscopic pneumatic dilatation or reoperative cardiomyotomy. ${ }^{57}$ In patients with prolonged symptoms the esophagus may be sigmoid shape which is thought to represent the most advanced stage of disease. Some surgeons recommend myotomy as the first line treatment and reserve esophageal resection for patients with persistent symptoms. ${ }^{19,55,56}$ Others recommend esophagectomy as the first-choice treatment believing that marked esophageal dilatation and redundancy predict the impossibility of improving emptying by means of myotomy. ${ }^{57,58}$ Furthermore achalasia is considered to be precancerous with a reported incidence of $0.2 \%-2.0 \% .^{59}$ The chronic irritation in achalasia leads to squamous hyperplasia which progress to dysplasia and eventually to carcinoma. $^{59}$ In addition, a p53 protein mutation study of the esophagus in patients with achalasia suggests that the entire esophagus may be in a precancerous state. ${ }^{60}$ We believe that every effort at preserving the native esophagus should be made before deciding to perform esophagectomy for a benign disease.

\section{Conclusion}

A lot of improvements have been made on the understanding of the etiology, pathophysiology and treatment of achalasia in the last two decades. Although different treatment options are available definitive cure is lacking. The choice of treatment involves the consideration of several clinical and economic factors. On the basis of evidence-based medicine, laparoscopic Heller's myotomy is currently the best treatment and should be considered as the initial treatment for most patients with achalasia. In developing countries where facilities are not readily 
available, open surgical myotomy remains an effective therapeutic option.

Because of the high probability of GER, it is considered prudent and reasonable to combine the myotomy with an antireflux procedure, preferentially a Dor or Toupet fundoplication. Pneumatic dilatation is an effective form of treatment and appears to be the most cost-effective alternative but its long-term efficacy is less than that of surgical myotomy. Endoscopic BTox injection is safe and effective but the effect diminishes over time and the need for multiple repeat injections must be considered. This may be the optimum treatment in patients with comorbidities or those whose life expectancy does not exceed 2 years. The usefulness of nifedipine and nitrates is minimal. These drugs should be used only on temporary basis, while waiting for more effective therapeutic options. Continued surveillance of treated patients is necessary because a few of them may require additional treatment irrespective of the initial therapeutic modality.

\section{References}

1. Willis T. Pharmaceutice ratioalis sive diatribe de medicamentarum operationibus in humano corpore. London: Hagia Comitis 1674.

2. Cheng YS, Li MH, Chen WX, Chen NW, Zhuang QX, Shang KZ. Selection and evaluation of three interventional procedures for achalasia based on long-term follow-up. World J Gastroenterol. 2003; 9:2370-2373.

3. Tsiaoussis J, Athanasakis E, Pechlivanides G, et al. Long-term functional results after laparoscopic surgery for oesophageal achalasia. Am J Surg. 2007; 193:26-31.

4. Gockel I, Bohl JR, Doostkam S, Eckardt VF, Junginger T. Spectrum of histopathological findings in patients with achalasia reflects different aetiologies. J Gastroenterol Hepatol. 2006; 21:727-733.

5. Emami $\mathrm{MH}$, Raisi $\mathrm{M}$, Amini J, Daghaghzadeh $\mathrm{H}$. Achalasia and thyroid disease. World J Gastroenterol. 2007; 13:594-599.

6. Ruiz-de-Leon A, Mendoza J, Sevill-Mantilla C, et al. Myenteric antiplexus antibodies and class II HLA in achalasia. Dig Dis Sci. 2002; 47:15-19.

7. Sachdev A, Sandhu BS. D'cruz S, Lehl SS, Agarwal V. Achalasia cardia in mother and son. Indian J Gastroenterol. 2004; 23:109.

8. Bern C, Montgomery SP, Herwaldt BL, Rassi A, Marin-Neto JA, Dantas RO. Evaluation and treatment of chagas disease in the United States. JAMA. 2007; 298:2171-2181.

9. Mayberry JF. Epidemiology and demographics of achalasia. Gastrointest Endosc Clin N Am. 2001; 11:235-248.
10. Nmadu PT. Achalasia of the oesophagus. Nigerian Journal of Surgical Sciences. 1993; 3:811.

11. Adebo OA, Grillo IA, Osinowo O, Adebonojo SA, Lewis EA. Oesophagotomy for achalasia of the oesophagus. Experience at the University College Hospital Ibadan. East Afr Med J. 1980; 57:390398.

12. Mbembati NAA, Lema LEK, Kahamba JF, Mcharo ONM. Operative management of achalasia of the oesophagus. East Afr Med J. 1994; 71:421-423.

13. Ho KY, Tay HH, Kang JY. A prospective study of the clinical features, manometric findings, incidence and prevalence of achalasia in Singapore. J Gastroenterol Hepatol. 1999; 14:791-795.

14. Torquati A, Richards WO, Holzman MD, Sharp KW. Laparoscopic myotomy for achalasia. Predictors of successful outcome after 200 cases. Ann Surg. 2006; 243:587-591.

15. Crookes PF, Corkill S, DeMeester TR. Gastoesophageal reflux in achalasia: When is 'reflux' really reflux? Dig Dis Sci. 1997; 42:13541361.

16. Bredenoord AJ, Tutian R, Smout AJ, Castell DO. Technology review: oesophageal impedence monitoring. Am J Gastroenterol. 2007; 102:187194.

17. Bedgood R, Sadurski R, Schade RR. The use of the internet in data assimilation in rare diseases. Dig Dis Sci. 2007; 52:307-312.

18. Onopriev VI, Durleshter VM, Ryabchun VV. Comparative pre and postoperative results analysis of functional state of the oesophagus assessment in patients with various stages of achalasia. Eur J Cardiothorac Surg. 2005; 28:1-6.

19. Khajanchee YS, Kanneganti S, Leatherwood AEB, Hansen PD, Swanstrom LL. Laparoscopic Heller myotomy with Toupet fundoplication. Arch Surg. 2005; 140:827-834.

20. Holloway RH. Oesophageal ultrasonography: A new view on oesophageal motility. Am J Gastroenterol. 2007; 102:146-148.

21. Eckardt VF. Schmitt, Kanzler G. Transabdominal ultrasonography in achalasia. Scand J Gastroenterol. 2004; 39:634-637.

22. Lake JM, Wong RKH. Review article: the management of achalasia- a comparison of different treatment modalities. Aliment Pharmacol Ther. 2006; 24:909-918.

23. Storr M, Allescher HD. Oesophageal pharmacology and treatment of primary motility disorders. Dis Esophagus. 1999; 12:241-257.

24. Traube M, Dubovik S, Lange RC, McCallum RW. The role of nifedipine therapy in achalasia: results of a randomized, double-blind, placebocontrolled study. Am J Gastroenterol. 1989; 84:1259-1262. 
25. Adler DG, Romero Y. Primary oesophageal motility disorders. Mayo Clin Proc. 2001; 76:195200.

26. Bortolotti M. Medical therapy of achalasia: a benefit reserved for a few. Digestion. 1999; 60:11-16.

27. Bortolotti M, Mari C, Lopilato C, Porrazzo G, Miglioli M. Effects of sildenafil on the oesophageal motility of patients with idiopathic achalasia. Gastroenterology. 2000; 118:253-257.

28. Zaninotto G, Annese V, Costantini $M$, et al. Randomized control trial of botulinum toxin versus laparoscopic Heller myotomy for oesophageal achalasia. Ann Surg. 2004; 239:36470.

29. Dressler D, Adib Saberi F. Botulinum toxin: mechanism of action. Eur Neurol. 2005; 53:3-9.

30. Annese V, Bassotti G. Non-surgical treatment of oesophageal achalasia. World J Gastroenterol. 2006; 12:5763-5766.

31. Pasricha PJ, Ravich WG, Hedrix TR, Sostre S, Jones B, Kalloo AN. Treatment of achalasia with intrasphincteric injection of botulinum toxin. A pilot trial. Ann Intern Med. 1994; 121:590-591.

32. Pasricha PJ, Ravich WG, Hedrix TR, Sostre S, Jones B, Kalloo AN. Intrasphincteric botulinum toxin for the treatment of achalasia. N Engl J Med. 1995; 332:774-778.

33. Vela MF, Ritcher JE, Wachsberger D, Cannor J, Rice TW. Complexities of managing achalasia at a tertiary referral centre: use of pneumatic dilatation, Heller myotomy and botulinum toxin injection. Am J Gastroenterol. 2004; 99:10291036.

34. Gideon RM, Castell DO, Yarze J. Prospective randomized comparison of pneumatic dilatation technique in patients with idiopathic achalasia. Dig Dis Sci. 1999; 44:1853-1857.

35. D'Onofrio V, Miletto P, Leandro G, laquinto G. Long-term follow-up of achalasia patients treated with botulinum toxin. Dig Liver Dis. 2002; 34:105-110.

36. Thomas V, Harish K, Sunilkumar K. Pneumatic dilation of achalasia cardia under direct endoscopy: the debate continues. Gastrointest Endosc. 2006; 63:734.

37. Lambroza A, Schuman RW. Pneumatic dilatation for achalasia without fluoroscopic guidance: safety and efficacy. Am J Gastroenterol. 1995; 90:1226-1229.

38. Lopushinsky SR, Urbach DR. Pneumatic dilatation and surgical myotomy for achalasia. JAMA. 2006; 296:2227-2233.

39. Gottstein G. Technik und klinik der oesophagus kopie. Mitt Grenzgeb Med Chir. 1981; 8:57-152.

40. Heller E. Extramukose cardioplastik bein chonischen cardiospasmus mit dilatation des oesophagus. Mitt Grenzgeb Med Chir. 1913; 27:147-149.
41. Zaaijer JH. Cardiospasm in the aged. Ann Surg. 1923; 77:615-617.

42. Garba ES. Achalasia and gastric outlet obstruction in a postmenopausal woman: case report. East Afr Med J. 2003; 80:165-166.

43. Gerson LB. Pneumatic dilatation or myotomy for achalasia? Gastroenterology. 2007; 132:811-813.

44. Junginger $T$, Kneist W, Sultanov F, Eckardt VF. Long-term outcome of myotomy and semifundoplication in achalasia. Chirurg. 2002; 73:704-709.

45. Shimi S, Nathanson LK, Cuschieri A. Laparoscopic cardiomyotomy for achalasia. J R Coll Surg Edinb. 1991; 36:152-154.

46. Bessell JR, Lally CJ, Schloithe A, Jamieson GG, Devitt PG, Watson DI. Laparoscopic cardiomyotomy for achalasia: long-term outcomes. ANZ J Surg. 2006; 76:558-562.

47. Melvin WS, Dundon JM, Talamini M, Horgan S. Computer enhanced robotic tele-surgery minimises oesophageal perforation during Heller myotomy. Surgery. 2005; 138:553-558.

48. Donahue PE, Teresi M, Patel S, Schlesinger PK. Laparoscopic myotomy in achalasia: intraoperative evidence of myotomy of the gastric cardia. Dis Esophagus. 1999; 12:30-36.

49. Arvelakis A, Karavokyros I, Bastounis E. Laparoscopic oesophagomyotomy for achalasia without complementary antireflux procedure. J Laparoendosc Adv Surg Tech A. 2006; 16:345349.

50. Lyass S, Thoman D, Steiner JP, Phillips E. Current status of an antireflux procedure in laparoscopic Heller myotomy. Surg Endosc. 2003; 17:554-558.

51. Porziella V, Cesario A, Granone P. Dor fundoplication after myotomy for achalasia: useful, unnecessary, or harmful? J Thorac Cardiovasc Surg. 2006; 132:216-217.

52. Kostic S, Kjellin A, Ruth $M$, et al. Pneumatic dilatation or laparoscopic cardiomyotomy in the management of newly diagnosed idiopathic achalasia: results of a randomized controlled trial. World J Surg. 2007; 31:470-478.

53. Goshal UC, Chaudhuri S, Pal BB, Dhar K, Ray G, Banerjee PK. Randomized controlled trial of intrasphincteric botulinum toxin-a injection versus balloon dilatation in the treatment of achalasia cardia. Dis Esophagus. 2001; 14:227231.

54. Parkman HP, Reynolds JC, Ouyang A, Rosato EF, Eisenberg JM, Cohen S. Pneumatic dilatation or oesophagomyotomy treatment for idiopathic achalasia: clinical outcomes and cost analysis. Dig Dis Sci. 1993; 38:75-85.

55. Ahmed A, Yusufu LMD, Ukwenya YA, Khalid L, Garba ES. Surgical management of achalasia in Zaria, Northern Nigeria. S Afr J Surg. 2008; 46:4851.

56. Mineo TC, Pompeo E. Long-term outcome of 
Heller myotomy in achalastic sigmoid oesophagus. J Thorac Cardiovasc Surg. 2004; 128:402-408.

57. Peters JH, Kauer WKH, Crookes PF, Ireland AP, Brenner CG, De-Meester TR. Oesophageal resection with colon interposition for end-stage achalasia. Arch Surg. 1995; 130:632-637.

58. Devaney EG, Lannettoni MD, Orringer MB, Marshal B. Esophagectomy for achalasia: patient selection and clinical experience. Ann Thorac Surg. 2001; 72:854-858.
59. Kawasaki N, Suzuki Y, Omura N, et al. Achalasia complicated by multiple intramucosal carcinomas: A case report. Surg Today. 2007; 37:897-900.

60. Lehman MB, Clark SB, Ormsby AH, Rice TW, Richter JE, Goldblum JR. Squamous mucosal alteration in oesophagectomy specimens from patients with end-stage achalasia. Am J Surg Pathol. 2001; 25:1413-1418. 